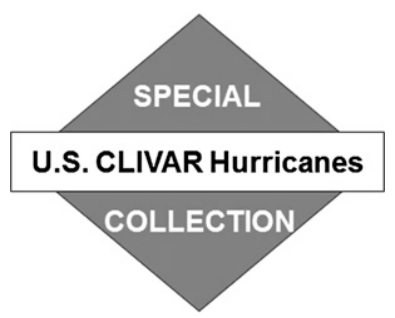

\title{
Sensitivity of Tropical Cyclone Rainfall to Idealized Global-Scale Forcings*
}

\author{
Gabriele Villarini, ${ }^{+}$DAVID A. LAVErs, ${ }^{+}$Enrico Scoccimarro, ${ }^{\#}$ Ming ZhaO,${ }^{@}$ \\ Michael F. Wehner, ${ }^{\&}$ GAbriel A. Vecchi, ${ }^{@}$ Thomas R. Knutson, ${ }^{@}$ AND Kevin A. ReeD** \\ ${ }^{+}$IIHR-Hydroscience \& Engineering, The University of Iowa, Iowa City, Iowa \\ ${ }^{\#}$ Istituto Nazionale di Geofisica e Vulcanologia, Bologna, and Centro Euro-Mediterraneo sui Cambiamenti Climatici, Lecce, Italy \\ ${ }^{\circledR}$ NOAA/Geophysical Fluid Dynamics Laboratory, Princeton, New Jersey \\ \& Lawrence Berkeley National Laboratory, Berkeley, California \\ ** National Center for Atmospheric Research, Boulder, Colorado
}

(Manuscript received 18 December 2013, in final form 4 March 2014)

\begin{abstract}
Heavy rainfall and flooding associated with tropical cyclones (TCs) are responsible for a large number of fatalities and economic damage worldwide. Despite their large socioeconomic impacts, research into heavy rainfall and flooding associated with TCs has received limited attention to date and still represents a major challenge. The capability to adapt to future changes in heavy rainfall and flooding associated with TCs is inextricably linked to and informed by understanding of the sensitivity of TC rainfall to likely future forcing mechanisms. Here a set of idealized high-resolution atmospheric model experiments produced as part of the U.S. Climate Variability and Predictability (CLIVAR) Hurricane Working Group activity is used to examine TC response to idealized global-scale perturbations: the doubling of $\mathrm{CO}_{2}$, uniform 2-K increases in global sea surface temperature (SST), and their combined impact. As a preliminary but key step, daily rainfall patterns of composite TCs within climate model outputs are first compared and contrasted to the observational records. To assess similarities and differences across different regions in response to the warming scenarios, analyses are performed at the global and hemispheric scales and in six global TC ocean basins. The results indicate a reduction in TC daily precipitation rates in the doubling $\mathrm{CO}_{2}$ scenario (on the order of $5 \%$ globally) and an increase in TC rainfall rates associated with a uniform increase of $2 \mathrm{~K}$ in SST (both alone and in combination with $\mathrm{CO}_{2}$ doubling; on the order of $10 \%-20 \%$ globally).
\end{abstract}

\section{Introduction}

Every year, tropical cyclones (TCs) are responsible for a large number of fatalities and vast economic damages (e.g., Rappaport 2000; Pielke et al. 2008; Zhang et al. 2009; Jonkman et al. 2009; Czajkowski et al. 2011, 2013; Mendelsohn et al. 2012; Peduzzi et al. 2012). To compound these TC hazards, over the last few decades there has been an increase in population and

\footnotetext{
* Supplemental information related to this paper is available at the Journals Online website: http://dx.doi.org/10.1175/JCLI-D-1300780.s1.

Corresponding author address: Gabriele Villarini, IIHRHydroscience \& Engineering, The University of Iowa, Iowa City, IA 52242.

E-mail: gabriele-villarini@uiowa.edu
}

infrastructure in global coastal regions resulting in increased TC-related damages (e.g., Mendelsohn et al. 2012; Peduzzi et al. 2012); this demographic change is acting in addition to the TC changes projected to occur as a result of climate change.

Although heavy rainfall is a major hazard associated with TCs, few studies have examined the rainfall patterns associated with these storms. A recent analysis of observations found that over the period 1994-2008 TCrelated heavy rainfall events in the United States occurred over twice as often as the long-term average (Kunkel et al. 2010). Using satellite-based estimates of rainfall, Lau and Zhou (2012) point to an increase in North Atlantic TC rainfall over the period 1988-2007. At the same time, they also identified a decrease in TC rainfall in the North Pacific. Over China, Ren et al. (2006) found decreasing trends in both TC total precipitation and frequency of torrential rain, while Ying

DOI: 10.1175/JCLI-D-13-00780.1 
et al. (2011) found increasing trends in the intensity of tropical cyclone precipitation at some locations over southeast China. Based on climate model outputs, Knutson and Tuleya (2004) found a tendency for larger near-storm precipitation rates in TCs in $\mathrm{CO}_{2}$ warming scenarios. In a review of TC and climate change studies, Knutson et al. (2010) found seven studies reporting an increase in TC-related rainfall (various metrics) under climate warming scenarios and no studies with decreases. Overall, TC-related rainfall rates are projected to increase on the order of $20 \%$ within $100 \mathrm{~km}$ from the storm center for the late twenty-first century (Knutson et al. 2010). More recently, Knutson et al. (2013) used a range of global climate models (GCMs), including outputs from climate models produced under phase 5 of the Coupled Model Intercomparison Project (CMIP5; Taylor et al. 2012), and found an increase in the average precipitation rate in North Atlantic TCs of about $10 \%$, rising to over $20 \%$ within $100 \mathrm{~km}$ of the storm center. Because of the observed and projected changes in TC rainfall and especially because of their large socioeconomic effects, it is essential to evaluate TC rainfall patterns under warming scenarios.

The main goals of this study are to undertake a globalscale analysis in six TC basins to analyze possible changes in TC rainfall under different warming scenarios using GCM runs. The research questions we will address are the following:

1) How well can GCMs reproduce the TC rainfall structure present in the observational records? Despite the simplicity of the question, very few studies have examined the capability of GCMs in reproducing the rainfall characteristics compared to the observational records.

2) What are the possible changes in TC rainfall that can be expected under different idealized warming scenarios? We will be able to address this question using a series of idealized experiments conducted in support of the U.S. Climate Variability and Predictability (CLIVAR) Hurricane and Climate Working Group.

The analyses will leverage on three state-of-the-art atmospheric models, and examine the changes in TC rainfall structure and magnitude in six TC genesis basins under three warming scenarios: 1) a doubling of $\mathrm{CO}_{2}$ in the atmosphere with no change in SST, 2) a uniform 2-K rise in global SST, and 3) a doubling of $\mathrm{CO}_{2}$ plus a uniform $2-\mathrm{K}$ rise in SST. The expectation prior to performing the analyses is for a decrease in TC rainfall under the $\mathrm{CO}_{2}$ doubling experiment and for an increase associated with the global increase in SST. It is more difficult to know a priori what to expect from a combination of changes in both $\mathrm{CO}_{2}$ and SST because of the potentially opposite effects associated with the changes in these two forcings. One of the main objectives of the U.S. CLIVAR working group, and these experiments, is to quantify changes in tropical cyclone characteristics in a warming climate.

This paper is organized as follows. The next section contains a description of the data, methods, and models used. Section 3 presents the results, and is followed by section 4 , in which we summarize the main points of this study.

\section{Data and methods}

Six TC genesis basins were used in this analysis, four in the Northern Hemisphere [North Atlantic (NA), eastern North Pacific (EP), western North Pacific (WP), and north Indian (NI) Ocean] and two in the Southern Hemisphere [south Indian (SI) Ocean and southern Pacific (SP)]. The delineation of these basins is the same as the one used in Camargo et al. (2005), with the only exception that we combine their Australian and South Pacific basins into the southern Pacific basin, which extends eastward from $110^{\circ} \mathrm{W}$ longitude, in order to have a larger storm sample. We also perform analyses at the global and hemispheric scales.

Observed TC tracks were taken from the International Best Track Archive for Climate Stewardship (IBTrACS v03r04; Knapp et al. 2010). It represents a unified database of global TC tracks, including data from numerous TC forecast centers around the world and other sources. The IBTrACS includes the latitude and longitude of the center of circulation of the recorded storms, maximum sustained wind, and minimum central pressure every $6 \mathrm{~h}$ during the storm lifetime. Here we focus on the period 1997-2012 because it matches the period for which relatively high-quality daily rainfall data are available globally.

Rainfall data are available over the period 1997-2012 through the Global Precipitation Climatology Project (GPCP; Huffman et al. 2001). This dataset provides global rainfall at the daily scale with a $1^{\circ} \times 1^{\circ}$ resolution. GPCP is obtained by merging different satellite-based rainfall estimates (in particular within and outside the latitude band of $40^{\circ} \mathrm{N}$ and $40^{\circ} \mathrm{S}$ ) and rain gauge data. Here GPCP is used as reference dataset for the comparison with modeled data. It is worth keeping in mind, though, that these are rainfall estimates based on satellite data, and not direct measurements of rainfall. Our assumption is that the uncertainties associated with this product are much smaller than what we would expect from modeled rainfall data.

These observational records will be used to evaluate the capability of three climate models in reproducing the 
rainfall characteristics associated with TCs. In this study we will use outputs from the Geophysical Fluid Dynamics Laboratory (GFDL) High Resolution Atmospheric Model (HiRAM), the Centro Euro-Mediterraneo sui Cambiamenti Climatici (CMCC) model, and the Community Atmosphere Model, version 5.1 (CAM5). The models are forced by climatological SSTs [1981-2005 average from the Hadley Centre Sea Ice and Sea Surface Temperature dataset (HadISST); Rayner et al. 2003]. The GCM run by CMCC builds on ECHAM5 (Roeckner et al. 2003) with the same resolution employed in the CMCC model fully coupled model (Scoccimarro et al. 2011): a spectral T159 horizontal resolution, corresponding to a Gaussian grid of about $0.75^{\circ} \times 0.75^{\circ}$, and a vertical resolution with 31 hybrid sigma-pressure levels with top at $10 \mathrm{hPa}$. The convection parameterization is based on the mass flux concept (Tiedtke 1989) modified following Nordeng (1994). Moist processes are treated using a massconserving algorithm for the transport of the different water species and potential chemical tracers (Lin and Rood 1996). The transport is resolved on the Gaussian grid. A more detailed description of the ECHAM5 atmospheric model performance can be found in Roeckner et al. (2006).

The model used for this study is a newer version of the GFDL HiRAM utilized in Zhao et al. (2009), Zhao and Held (2010), and Held and Zhao (2011) for studies of global hurricane climatology, variability, and change with global warming. It is a $50-\mathrm{km}$-resolution model using a cubed-sphere dynamical core and the Bretherton et al. (2004) convection scheme for both shallow and deep cumulus clouds. The main difference in the newer version is that it incorporates a new land model (GFDL LM3). The atmospheric dynamical core of the model was also updated to improve efficiency and stability. As a result of these changes, there are minor retunings of the atmospheric parameters in the cloud and surface boundary layer parameterizations necessary to achieve the top-of-atmosphere (TOA) radiative balance (Zhao et al. 2012). This model is also the version of HiRAM used for the GFDL participation in the Fifth Assessment Report of the Intergovernmental Panel on Climate Change (IPCC AR5) high-resolution time-slice simulations.

The CAM5, developed by the U.S. Department of Energy and the National Science Foundation, was integrated using a finite-volume dynamical core on a latitudelongitude mesh of approximately $0.25^{\circ}$ with 30 vertical levels (Bacmeister et al. 2014; Wehner et al. 2013, manuscript submitted to J. Model. Earth Syst.). The CAM5 physical parameterization package uses the Zhang and McFarlane (1995) deep convective parameterization and the University of Washington (UW) shallow convection scheme (Park and Bretherton 2009). The convective parameterization includes a dilute entraining plume (Neale et al. 2008) and a convective momentum transport approximation as used in the previous version of the model, CAM4 (Richter and Rasch 2008). The moist boundary layer turbulence scheme is that of Bretherton and Park (2009). A description of the surface flux parameterizations, an important driver for tropical cyclogenesis, is described in Neale et al. (2012).

Each model had four simulations: 1) present day (Present Day), 2) a doubling of $\mathrm{CO}_{2}$ in the atmosphere $\left.\left(2 \times \mathrm{CO}_{2}\right), 3\right)$ a uniform $2-\mathrm{K}$ rise in SST $(+2 \mathrm{~K})$, and 4$)$ a doubling of $\mathrm{CO}_{2}$ plus a uniform $2-\mathrm{K}$ rise in SST $\left(2 \times \mathrm{CO}_{2}+2 \mathrm{~K}\right)$. The number of years in terms of rainfall data varied from model to model $(20 \mathrm{yr}$ for the GDFL model, $10 \mathrm{yr}$ for the CMCC model, and $9 \mathrm{yr}$ for the CAM5). The tracking algorithm used to identify TCs in the GFDL model outputs is similar to what is described in Zhao et al. (2009). The tracking for the CMCC model is based on Walsh (1997) and Walsh et al. (2007). Detailed information on the ability of climate models in representing TCs can be found in Walsh et al. (2013). The tracking algorithm for the CAM5 follows closely the method and thresholds of Knutson et al. (2007) and has been generalized to execute efficiently on very large numbers of processors (Prabhat et al. 2012).

Here we focus on the evaluation of the highest rainproducing TCs both in the models and observations. For each 1200 UTC time step of each TC in the IBTrACS or in the GFDL model, CMCC model, and CAM5, the rainfall in a $10^{\circ} \times 10^{\circ}$ grid around the center of circulation of the storm was extracted based on the information available in the track files; these rainfall fields represent daily rainfall accumulations and were then averaged over the storm lifetime to form a gridded composite mean of the daily rainfall associated with a particular storm. We note that only time steps when the TC center was south of $30^{\circ} \mathrm{N}$ (for the Northern Hemisphere) or north of $30^{\circ} \mathrm{S}$ (for the Southern Hemisphere) were used to guard against extratropical dynamics affecting the TC rainfall patterns. The composite mean TC rainfall patterns were then ranked according to the highest average rainfall within a $5^{\circ}$ radius around the TC center, and the top $10 \%$ of the TCs were selected. The selection of a $5^{\circ}$ radius around the TC center is consistent with other studies in the literature (e.g., Hart and Evans 2001; Ren et al. 2006; Kunkel et al. 2010). We use a percentage rather than a specific number of storms to account for differences in the number of TCs in different basins and among the models. Finally all the TC time steps (or storm days) in the top $10 \%$ of TCs were averaged to produce a composite mean of the TC 
storm days. Table S1 in the supplementary material summarizes the number of TC storm days for each model, scenario, and basin. The western Pacific is the Northern Hemispheric basin with the largest number of TC days with the exception of CAM5 (possibly due to a TC genesis more in the central Pacific, resulting in storms counted in the eastern Pacific). We also notice the low TC activity in the CMCC model in the North Atlantic and eastern Pacific because of this model's known issues in generating TCs in these basins (Scoccimarro et al. 2011). The results presented in the next section are related to TC daily rainfall for the top $10 \%$ rainiest TCs.

\section{Results}

\section{a. Observations}

Figure 1 is based on GPCP data and shows the composite mean precipitation patterns associated with the top $10 \%$ rainiest TCs in each of the six basins, together with the corresponding hemispheric composites. For the Northern Hemisphere, the rainfall patterns have a southwest-northeast orientation. The areas with maximum rainfall vary among the basins, from the eastern quadrants in the North Atlantic to the southwest quadrant in the western Pacific; these differences may partly be an artefact of the coarse resolution of GPCP $\left(1^{\circ} \times 1^{\circ}\right)$, but are also likely to be associated with the different storm morphology in these basins. There is also a large spread in the number of TC storm days used in the composites, with the north Indian Ocean basin having the fewest and the western Pacific the most fields used (see panel titles in Fig. 1). The average rainfall footprint is also very different from basin to basin. Most of the rainfall is concentrated within a $5^{\circ}$ radius for the North Atlantic and the eastern Pacific, with the latter showing the smallest rainfall averages among the basins in the Northern Hemisphere. On the other hand, the rainfall footprint for the western Pacific is much larger, consistent with the discussion in Chan and Chan (2012) related to the storm size in these basins. Overall, the TCs in the Northern Hemisphere present a well-defined structure, with the largest composite daily rainfall close to the center of circulation of the storms and decreasing as we move farther away.

In the Southern Hemisphere the rainfall patterns tend to be mirror images of those observed in the Northern Hemisphere, with a northwest-southeast structure, and the areas of maximum composite rainfall predominantly occurring in the southeast TC quadrant. Beside the fact that over the 1997-2012 period there were more than twice as many TC days in the Northern Hemisphere compared with the Southern Hemisphere, another difference is related to the rainfall magnitudes. In the Southern Hemisphere, while most of the (storm relative) rainfall is within a $5^{\circ}$ radius of the storm center, on average the rainfall intensities are lower than in the northern ocean basins. Part of the asymmetry in the rainfall patterns could be a result of the storm motion and the fact that we are working with rainfall at the daily scale.

The median radial profiles of composite TC rainfall rates have similar structure among the different basins, with the highest rainfall rates near the center of circulation (Fig. 2), and differences that are related to the different interactions that these storms have with the environment in which they develop in each basin (Lonfat et al. 2004). Owing to the coarse GPCP resolution $\left(1^{\circ} \times 1^{\circ}\right)$ the eyewall structure is not captured in these profiles. These profiles are similar to the ones described in Jiang et al. (2008) for the North Atlantic and Lonfat et al. (2004) at the global scale once we account for GPCP's coarser resolution. More specifically, the TCs in the north Indian Ocean basin have the largest rainfall rates close to the center of circulation, and a rapid decrease as distance from the $\mathrm{TC}$ center increases. The storms in the western Pacific have the largest composite daily rainfall rates overall, in agreement with the results in Fig. 1. Conversely, the eastern Pacific TCs are generally characterized by the smallest rainfall rates. Compared to the south Indian Ocean basin, the average daily rainfall rates associated with storms in the southern Pacific is consistently larger for any distance from the storm center. The results for both hemispheres are consistent with the rainfall profiles in Lonfat et al. (2004).

\section{b. Models}

In this subsection we compare the rainfall patterns for the three models and examine the TC rainfall response to the three idealized warming scenarios. We will start with results at the global (Fig. 3) and hemispheric scales (Figs. S1, S2 in the supplementary material) and then examine changes in TC rainfall in each of the six ocean basins. At the global scale, the three models provide a consistent response to the different scenarios. In the $2 \times \mathrm{CO}_{2}$ run the intensity of the composite $\mathrm{TC}$ rainfall weakens compared to the Present Day run. The reduction resulting from $2 \times \mathrm{CO}_{2}$ may be due to two superimposing components. The first is a reduction in global mean precipitation associated with a weaker radiative cooling rate resulting from a doubling in $\mathrm{CO}_{2}$. The second is a weakening of TC intensity because of an increase in surface relative humidity and a slight increase of tropospheric stability (e.g., Sugi and Yoshimura 2004; Yoshimura and Sugi 2005; Held and Zhao 2011; Zhao 

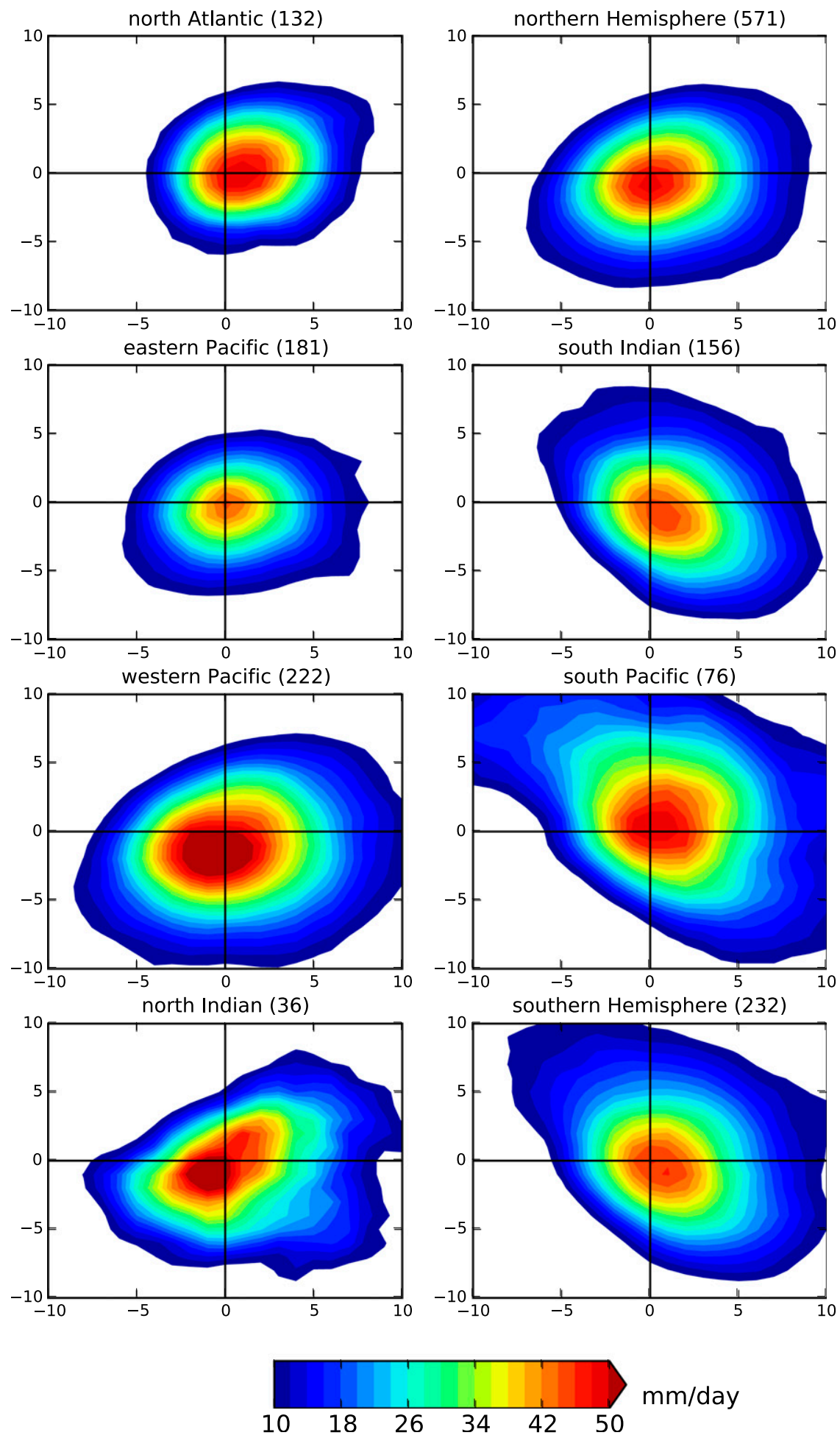

FIG. 1. Composite mean observed (GPCP) daily rainfall rate $\left(\mathrm{mm} \mathrm{day}^{-1}\right)$ patterns in the six ocean basins, as well as the composites for the Northern and Southern Hemisphere top $10 \%$ rainiest TCs. The number of TC storm days used in the composite is given in the panel titles. The $x$ and $y$ axes correspond to degrees from the TC center. 

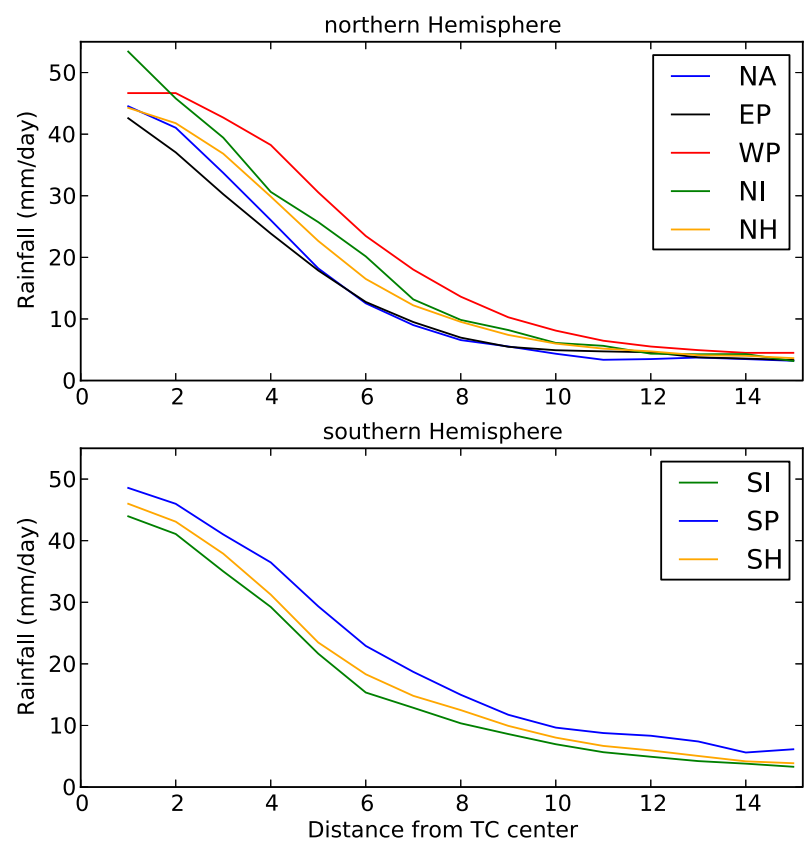

FIG. 2. (top) Median radial rainfall profiles $\left(\mathrm{mm} \mathrm{day}^{-1}\right)$ for the Northern Hemispheric basins including the NA, EP, WP, NI, and all NH basins. (bottom) Median radial rainfall profiles $\left(\mathrm{mm} \mathrm{day}^{-1}\right.$ ) for the Southern Hemispheric basins including the SI, SP, and all $\mathrm{SH}$ basins. The $x$ axis corresponds to degrees from the TC center.

et al. 2013). The $+2 \mathrm{~K}$ and $2 \times \mathrm{CO}_{2}+2 \mathrm{~K}$ simulations both have higher rainfall than in the Present Day one, which is due to the increased SST that leads to higher air temperatures, higher water vapor content, and increased rainfall (Scoccimarro et al. 2014). Yoshimura and Sugi (2005) discuss the opposing effects of increasing SST and $\mathrm{CO}_{2}$ in terms of precipitation and dry static stability. Our analyses lead to similar conclusions when we stratify the results into the Northern and Southern Hemispheres (Figs. S1, S2 in the supplementary material). Based on the summary values in Table 1 for area- and daily-averaged precipitation associated with the top $10 \%$ rainiest TCs, our modeling results indicate a reduction in precipitation in the doubling $\mathrm{CO}_{2}$ scenario on the order of $5 \%$ globally, and an increase in composite TC rainfall associated with a uniform increase of $2 \mathrm{~K}$ in SST (both alone and in combination with $\mathrm{CO}_{2}$ doubling) on the order of $10 \%-$ $20 \%$ globally.

After performing analyses at the global and hemispheric scales, we focus on each individual ocean basin, comparing and contrasting the results from the three models under the three warming scenarios at a much more regional scale. We start with the GFDL model. The composite mean TC rainfall patterns for the four Northern Hemispheric basins for the Present Day and three warming simulations are shown in Fig. 4. For the most part the patterns have an ellipsoidal shape, with some structures exhibiting the expected southwestnortheast shape in the Northern Hemisphere. Moreover, the rainfall patterns in the different basins tend to be similar to the observations, with the TCs in the western (eastern) Pacific having the largest (smallest) footprints. All basins, however, have maximum composite TC rainfall occurring in the top-left quadrant, which differs from the observed patterns (Fig. 1). Generally, the TC rainfall intensities are comparable to the observations, with a tendency toward overestimation. To the best of our knowledge, this is the first time that global comparisons between observed and simulated TC rainfall composites have been performed.

Keeping in mind these similarities and differences between modeled and observed rainfall while interpreting the following results, we now examine the potential changes in TC rainfall under three different scenarios based on the GFDL model. In the $2 \times \mathrm{CO}_{2}$ run (Fig. 4, center-left panels) the intensity of the composite TC rainfall weakens compared to the Present Day simulation $(\sim 5 \%-15 \%$; Table 1$)$, as shown by the reduced footprint of the largest rainfall areas. In this run, the atmospheric radiative cooling rate decreases because of a reduction of TOA outgoing longwave radiative flux. In an equilibrium state, the reduction in atmospheric radiative cooling rate must be balanced by a reduction in precipitation and surface evaporation. Since surface winds do not change significantly in these experiments, the surface relative humidity must increase. The increase of surface relative humidity reduces the surface evaporation potential (or thermodynamic disequilibrium), which is the primarily driving force for TC genesis and intensity. Thus, we suggest that the above mechanism explains much of the general reduction of TC rainfall intensity in the $2 \times \mathrm{CO}_{2}$ case. In addition, the increase in $\mathrm{CO}_{2}$ concentration tends to slightly warm the surface temperature over tropical land, which leads to slight warmer upper tropospheric temperature, contributing to a slight increase in tropospheric stability. This is a second mechanism which is likely partly responsible for the reduction in rainfall intensity in the $2 \times \mathrm{CO}_{2}$ case. The $+2 \mathrm{~K}$ and $2 \times \mathrm{CO}_{2}+2 \mathrm{~K}$ simulations both have higher TC rainfall rates than in the Present Day run (up to $25 \%$ in the eastern Pacific; Table 1). These results are valid for all the Northern Hemispheric basins, with the exception of the North Atlantic, where TC rainfall intensity is higher than the Present Day run for the $+2 \mathrm{~K}$ but not for the $2 \times \mathrm{CO}_{2}+2 \mathrm{~K}$ simulation (Table 1).

These results are corroborated in the median TC radial rainfall profiles in Fig. 5 computed based on the top $10 \%$ rainiest TCs; the simulations for a $2-\mathrm{K}$ increase in global SST (whether with or without doubling $\mathrm{CO}_{2}$ ) show the largest increase in rainfall at all distances. 

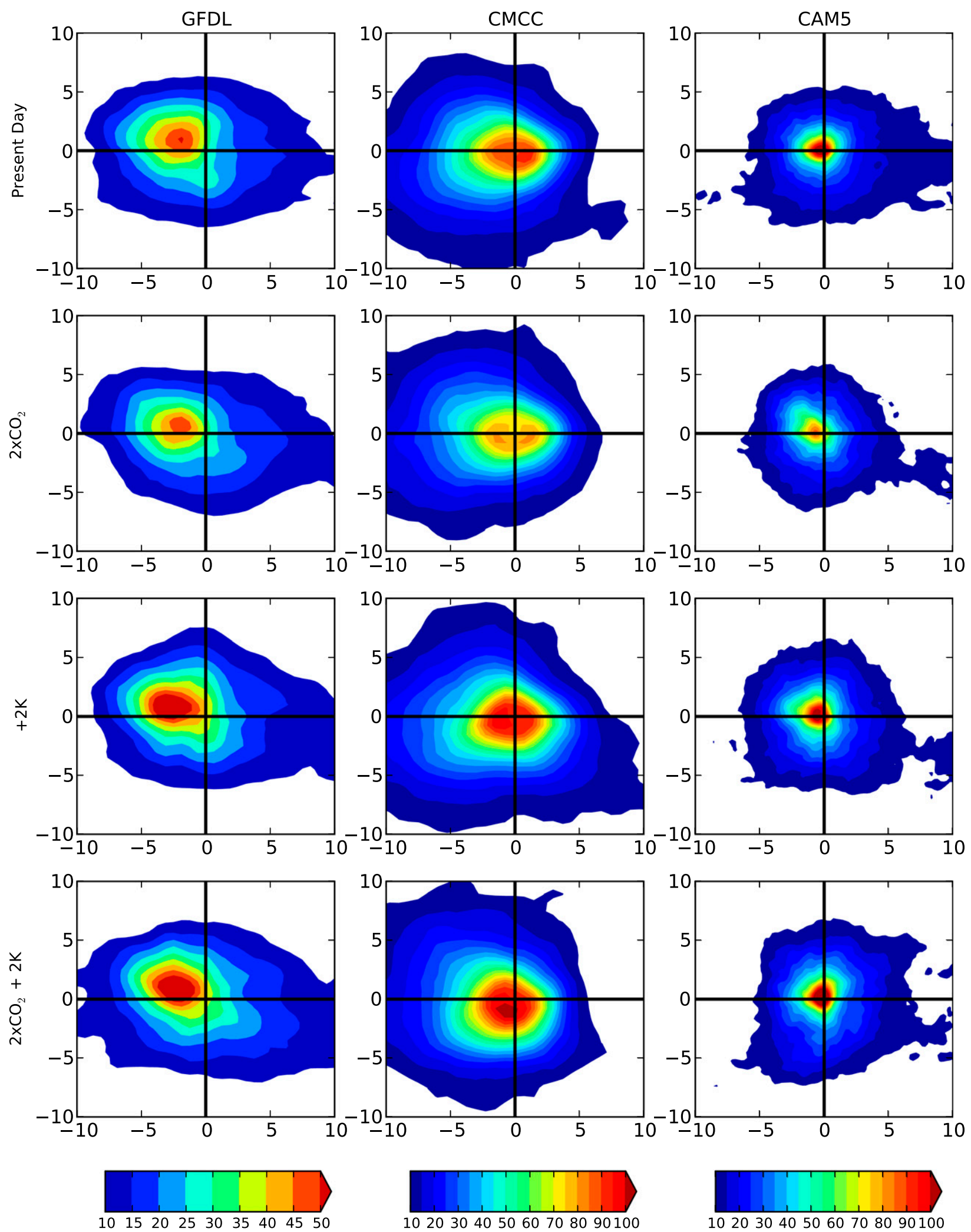

FIG. 3. Composite weighted mean daily rainfall rate patterns $\left(\mathrm{mm} \mathrm{day}^{-1}\right)$ at the global scale for each of the three models and the different scenarios. The weights are computed based on the number of TC storm days in each basin (see Table S1 in the supplementary material). The $x$ and $y$ axes correspond to degrees from the TC center. Note that the color bar extends over a different range for the GFDL model. 
TABLE 1. Percentage changes of the three warming scenarios with respect for the Present Day runs for the three models for the different basins and at the global and hemispheric scales. Results are representative of a $5^{\circ}$ radius area around the center of circulation for each storm.

\begin{tabular}{|c|c|c|c|c|c|c|c|c|c|}
\hline & \multicolumn{3}{|c|}{ GFDL HiRAM } & \multicolumn{3}{|c|}{ CMCC model } & \multicolumn{3}{|c|}{ CAM5 } \\
\hline & $2 \times \mathrm{CO}_{2}$ & $+2 \mathrm{~K}$ & $2 \times \mathrm{CO}_{2}+2 \mathrm{~K}$ & $2 \times \mathrm{CO}_{2}$ & $+2 \mathrm{~K}$ & $2 \times \mathrm{CO}_{2}+2 \mathrm{~K}$ & $2 \times \mathrm{CO}_{2}$ & $+2 \mathrm{~K}$ & $2 \times \mathrm{CO}_{2}+2 \mathrm{~K}$ \\
\hline Global & -6.1 & 9.1 & 11.7 & -5.4 & 10.7 & 12.8 & -1.4 & 13.2 & 16.5 \\
\hline $\mathrm{NH}$ & -8.9 & 7.8 & 13.3 & -6.7 & 15.7 & 17.1 & 1.3 & 14.1 & 16.1 \\
\hline $\mathrm{SH}$ & 0.4 & 12.6 & 8.8 & -6.2 & 0.9 & 4.5 & -8.0 & 10.1 & 18.0 \\
\hline North Atlantic & -16.7 & 18.2 & -11.8 & -1.8 & 4.5 & 11.1 & -8.4 & -0.4 & 8.5 \\
\hline East Pacific & -6.5 & 25.1 & 17.0 & -6.0 & 14.0 & 24.3 & 12.9 & 17.0 & 27.8 \\
\hline West Pacific & -5.9 & 2.5 & 16.5 & -8.1 & 15.8 & 14.8 & -11.1 & 17.1 & 3.7 \\
\hline North Indian Ocean & -17.7 & 0.2 & 17.6 & 1.7 & 21.0 & 21.2 & -1.5 & 18.7 & 19.2 \\
\hline South Indian Ocean & 1.1 & 7.3 & 5.8 & -9.5 & -1.8 & -1.4 & -7.6 & 16.4 & 25.6 \\
\hline South Pacific & -0.9 & 19.9 & 12.9 & -4.5 & 1.8 & 5.3 & -10.3 & -0.3 & 10.6 \\
\hline
\end{tabular}

Similarly, a doubling of $\mathrm{CO}_{2}$ alone results in a rainfall decrease at most ranges. These TC rainfall profiles also highlight the capability of the GFDL model in capturing how the largest daily rainfall rates occur away from the storm center (approximately between $2^{\circ}$ and $4^{\circ}$ ). These results are consistent with Lonfat et al. (2004) and Jiang et al. (2008), even though the maximum herein tends to occur farther away than in the aforementioned observational studies.

In the south Indian Ocean and southern Pacific basins, the maximum TC rainfall from the GFDL model is mostly in the bottom-left quadrant, the opposite of the Northern Hemisphere (cf. Figs. 4 and 6). There is some evidence for the southeast-northwest orientation in the composite mean rainfall patterns, although the structures are not as well defined as in the observations (Fig. 1). Moreover, there a tendency toward larger average $\mathrm{TC}$ rainfall values.

The rainfall response for the south Indian Ocean and southern Pacific basins to different warming scenarios in the GFDL model is generally similar to the changes for the basins in the Northern Hemisphere. The increase in global SST results in an overall increase in TC daily rainfall rates (Table 1); on the other hand, a doubling of $\mathrm{CO}_{2}$ results in comparable average rainfall values (Table 1). The median rainfall profiles in Fig. 5 (bottom panels) highlight the differences in responses for the two basins. While for the southern Indian Ocean basin the median rainfall profiles tend to be generally very similar regardless of the warming scenario, we observe more variability in the southern Pacific. Interestingly, the TC rainfall in the $+2 \mathrm{~K}$ scenarios is generally the largest close to the center of circulation, whereas it is the smallest for the $2 \times \mathrm{CO}_{2}$ one. On the other hand, as we move away from the center of the storm, the largest rainfall intensities are for the $2 \times \mathrm{CO}_{2}$ scenario. These results suggest that by doubling $\mathrm{CO}_{2}$ we should expect a rainfall decrease close to the center of the storm but also a widening of the areas associated with heavier rainfall.
We have also examined the potential changes in daily $\mathrm{TC}$ rainfall rates associated with a $2-\mathrm{K}$ increase in SST based on the Clausius-Clapeyron relationship (14\% increase in the Present Day scenario; Fig. 5). For the North Atlantic, Knutson et al. (2013) found that the use of the Clausius-Clapeyron relationship was able to well describe the TC rainfall rate changes at $200-400 \mathrm{~km}$ from the center of circulation, while other processes were dominant at shorter distances. In our study and based on the GFDL global model, it is hard to find consistent results across basins and range. In the North Atlantic and southern Pacific basins, the TC rainfall changes in the $+2 \mathrm{~K}$ scenario are in general agreement with what we would expect based on the ClausiusClapeyron relationship. On the other hand, with the exception of the eastern Pacific, the rainfall increases in the other basins are less than what expected based on a $7 \% \mathrm{~K}^{-1}$ increase in atmospheric humidity.

The regional rainfall composite and profile results for the CMCC model are similar to the ones presented for the GFDL model for the six ocean basins and the three warming scenarios. Note that the analyses related to the North Atlantic are presented but not discussed because of the known issues that the CMCC model has in generating TCs in this basin (Scoccimarro et al. 2011). The same holds for the eastern Pacific, for which the number of TC days used to compute the rainfall composites and profiles is much smaller than in the observations and in the GFDL model. These deficiencies in sample size are too large to be ascribed to the shorter records available for the CMCC model (10yr) and are more likely due to simulation deficiencies of the model.

Figure 7 shows the composite TC daily rainfall patterns for the basins in the Northern Hemisphere for the CMCC model. The rainfall composites for the storms in the western Pacific and the north Indian Ocean basins exhibit structures similar to those for the observations (Fig. 1), even though the TC rainfall amounts are 

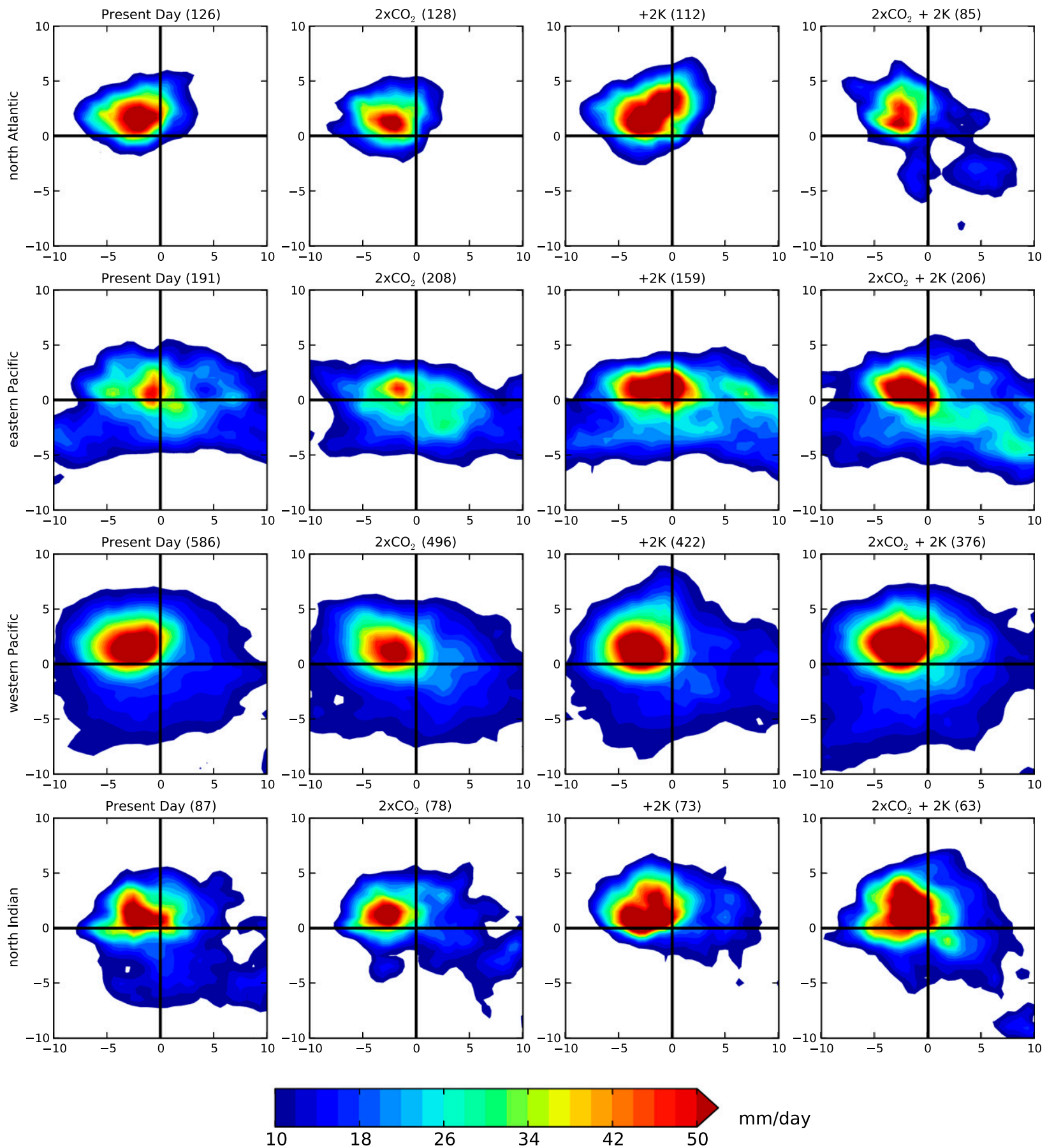

FIG. 4. Composite mean daily rainfall patterns $\left(\mathrm{mm} \mathrm{day}^{-1}\right)$ for the storm days in the top $10 \%$ rainiest TCs in (left)-(right) the four GFDL simulations and in (top)-(bottom) the four NH TC basins. The number of TC storm days used in each composite is given in the panel titles in parentheses, and the $x$ and $y$ axes correspond to degrees from the TC center of circulation.

generally larger. Moreover, the location of the areas with the largest rainfall amounts is similar to those identified in the observations. The changes in rainfall patterns for the different scenarios lead us to the same conclusions as those drawn for the GFDL model.
By increasing the global SST by $2 \mathrm{~K}$, there is an increase in composite TC rainfall rates in the western Pacific and the north Indian Oceans for the CMCC model. At the same time, rainfall rates tend to decrease for the doubled $\mathrm{CO}_{2}$ case (Table 1). This holds for both 

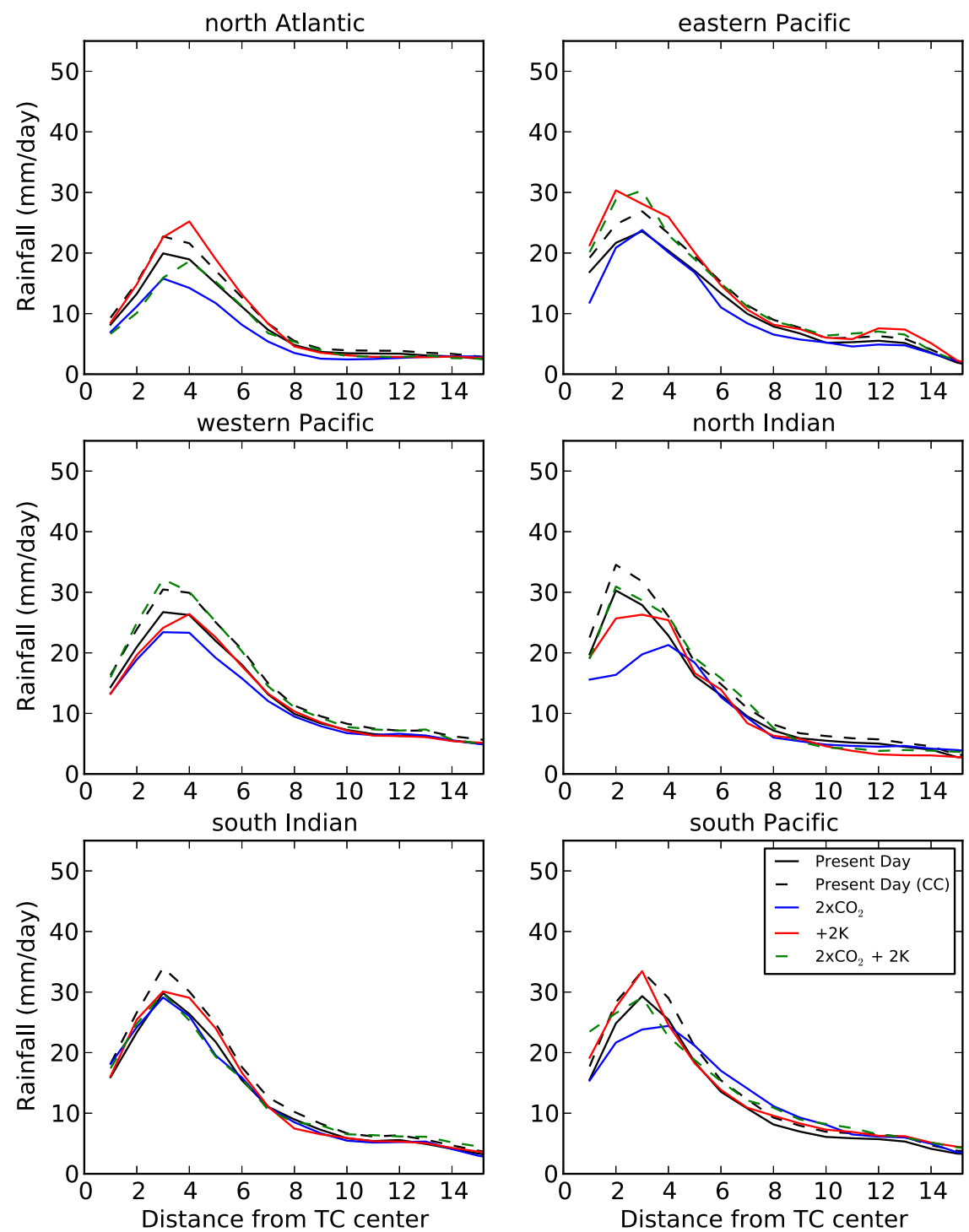

FIG. 5. Median radial rainfall profiles for the (top),(middle) NH and (bottom) SH basins in the four GFDL simulations. The $x$ axis corresponds to degrees from the TC center. The line "Present Day (CC)" refers to the rainfall profile for the Present Day simulation increased by $14 \%$, corresponding to a moisture increase according to the Clausius-Clapeyron relationship for a $2-\mathrm{K}$ increase in SST. The bin size is $1^{\circ}$.

rainfall mean composites (Fig. 7) and median radial profiles (Fig. 8). Despite the coarser resolution of the CMCC model, there are still indications that the rainfall tends to increase from the center of the storm up to about $2^{\circ}-3^{\circ}$ radius, and decrease afterward.

In the Southern Hemisphere the TC rainfall patterns from the CMCC model are similar to the observations (Fig. 9). The major rainfall axis is oriented northwest to southeast as in Fig. 1, even though the average rainfall tends to be higher than observed. The different warming scenarios provide results consistent with the Northern Hemisphere, as well as with those from the GFDL model. The global increase in SST results in an increase in $\mathrm{TC}$ rainfall rates, which is more marked closer to the center of the storms. On the other hand, in the $2 \times \mathrm{CO}_{2}$ scenario we observe a reduction in rainfall rates, with a narrowing of the areas of higher rainfall close to the center of circulation. These conclusions are also supported by the analyses of the rainfall profiles (Fig. 8, bottom panels), in which warmer SST tends to translate to larger rainfall amounts, with some differences depending on the distance from the center (possibly related to the asymmetry of the precipitation near the center of the storms and changes in the location of 

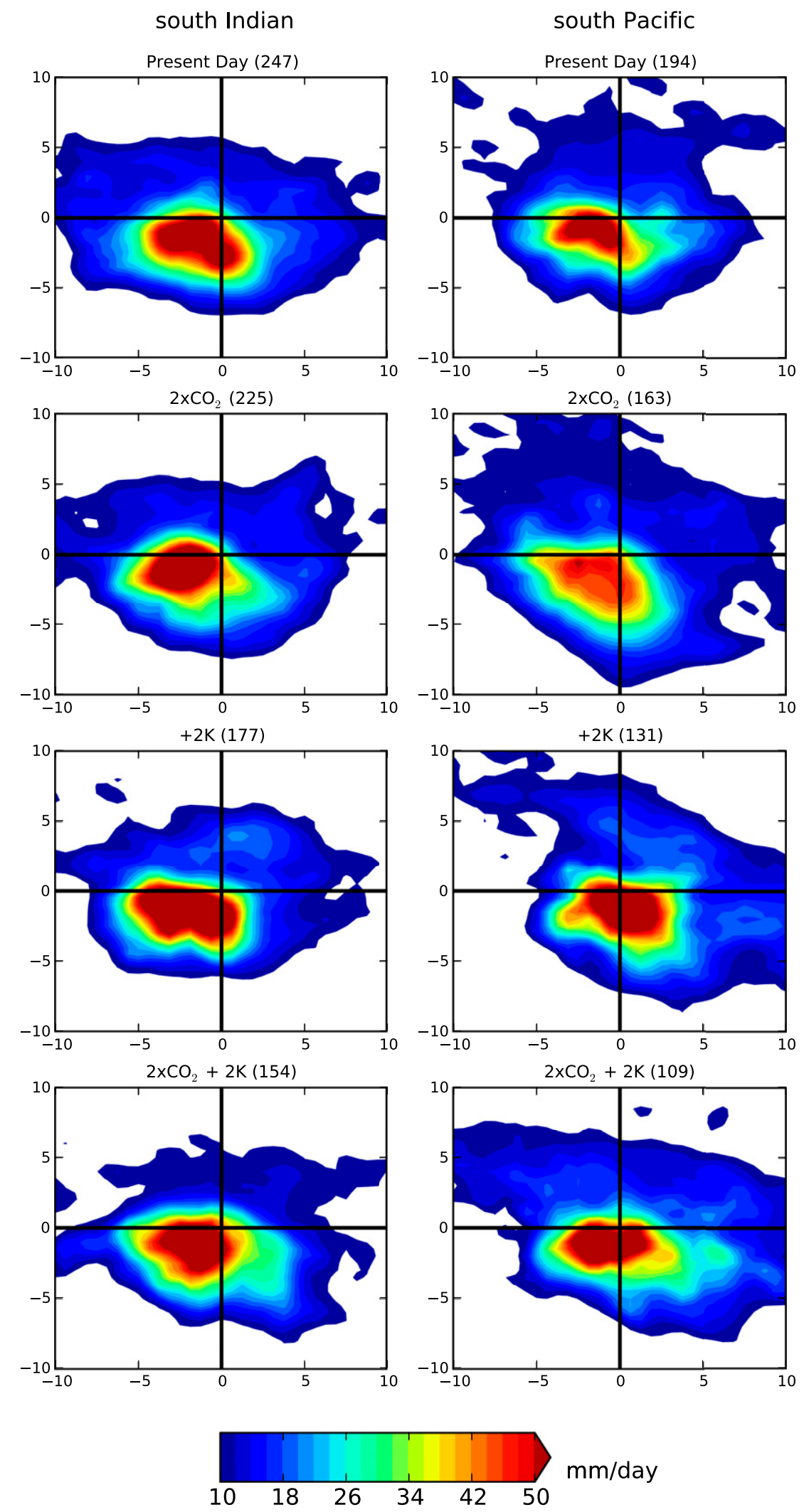

FIG. 6. Composite mean daily rainfall patterns $\left(\mathrm{mm} \mathrm{day}^{-1}\right)$ for the storm days in the top $10 \%$ rainiest TCs in (top)-(bottom) the four GFDL simulations and in (left),(right) the two SH TC basins. The number of TC storm days used in each composite is given in the panel titles, and the $x$ and $y$ axes correspond to degrees from the TC center. 

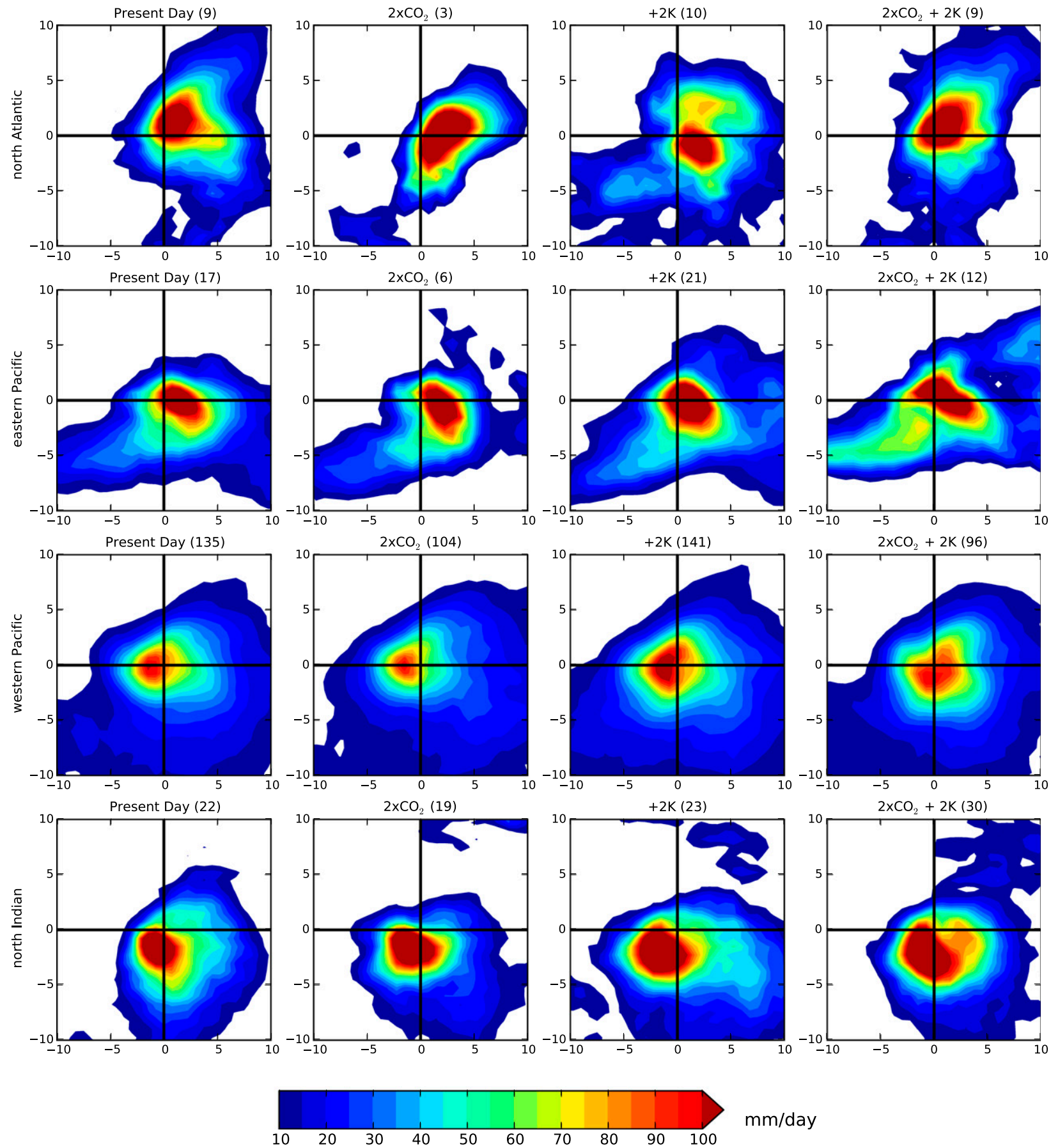

FIG. 7. As in Fig. 4, but for the CMCC model. Note that the color bar extends over twice the range in Fig. 4.

maximum rainfall). If we try to interpret the changes in rainfall profile using the Clausius-Clapeyron relationship, we have results similar to those for the GFDL model, with the profiles for the $+2 \mathrm{~K}$ scenario exhibiting less rainfall than expected according to a $7 \% \mathrm{~K}^{-1}$ increase in atmospheric moisture. There is actually a better agreement between the $2 \times \mathrm{CO}_{2}+2 \mathrm{~K}$ profiles and those based on a $14 \%$ increase in rainfall from the Present Day scenario.

The CAM5 is the model with the highest spatial resolution (approximately $0.25^{\circ}$ ). There are both similarities and differences with respect to the observational record and the other two models at the ocean-basin scale. Qualitatively, the TC rainfall patterns for the Present 

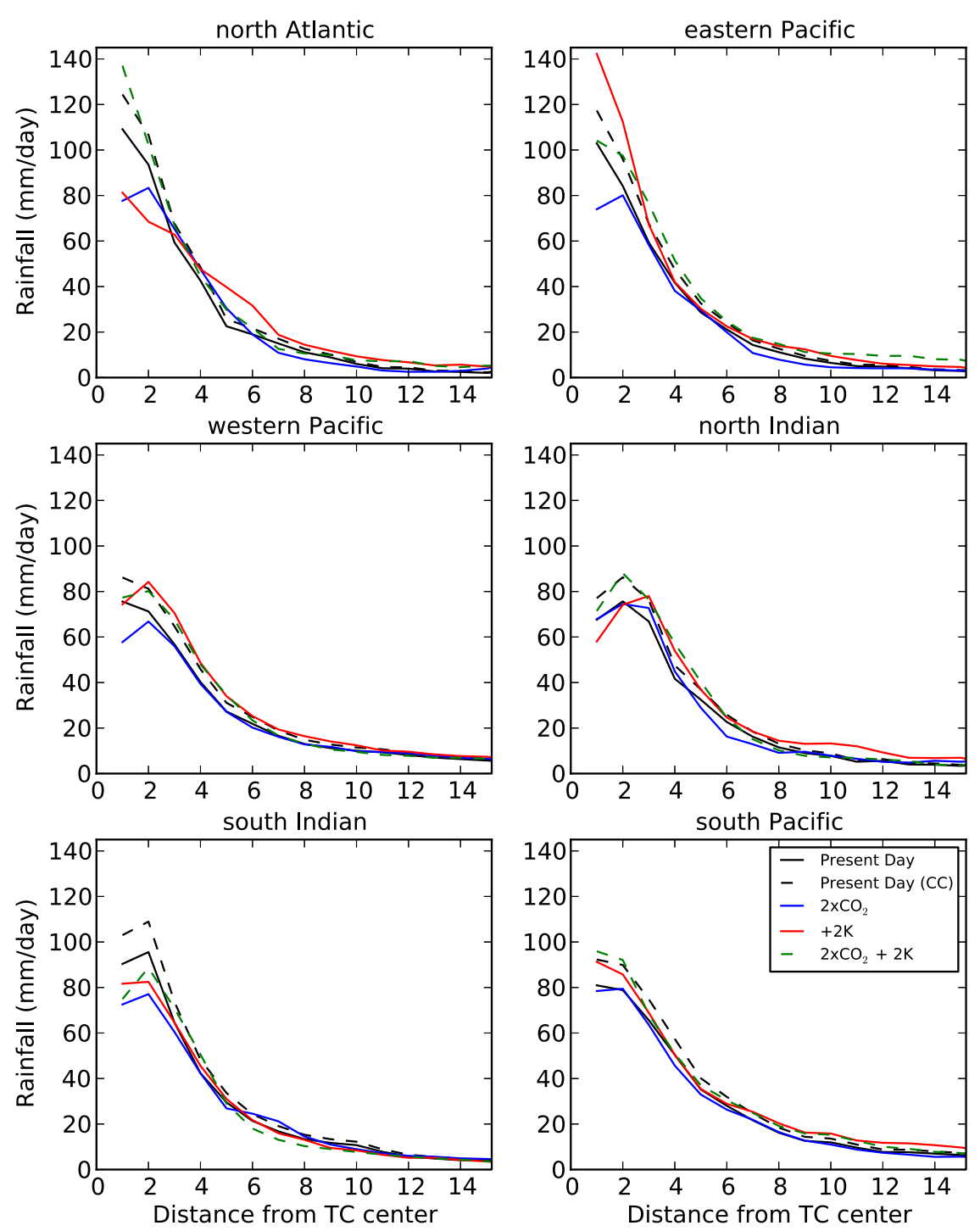

FIG. 8. As in Fig. 5, but for the CMCC model.

Day runs are consistent with the observations and the other models, even though the rainfall values tend to be larger than those based on GPCP and the fields are less smooth because of the higher spatial resolution (Fig. 10). There are a few differences in terms of the TC rainfall days. In the observations and the GFDL and CMCC models, the western Pacific has the largest number of TC days, followed by the eastern Pacific. For the CAM5, on the other hand, the number of TC storm days is the largest for the eastern Pacific, followed by the western Pacific. Despite the differences in TC days, the storms in the western Pacific are the ones with the largest composite rainfall footprint followed by the North Atlantic TCs. Finally, while the CMCC and GFDL models and observations indicate that the rainfall associated with eastern Pacific TCs is the smallest among the basins in the
Northern Hemisphere, this is not the case for the CAM5, for which storms in the north Indian Ocean have the smallest rainfall values.

Examination of the model results for the three warming scenarios for the CAM5 does not allow a consistent interpretation of the results for all the basins. Compared to the Present Day climate runs (Table 1), the rainfall associated with North Atlantic, western Pacific, and north Indian Ocean TCs decreases for a doubling in $\mathrm{CO}_{2}$, whereas it increases for the eastern Pacific storms. On the other hand, there is a general increase in TC rainfall rates for the two scenarios involving a $+2-\mathrm{K}$ increase in global SST (Table 1). The differences among scenarios can also be assessed for different distances from the center of circulation (Fig. 11, top and middle panels). Despite the finer resolution, 

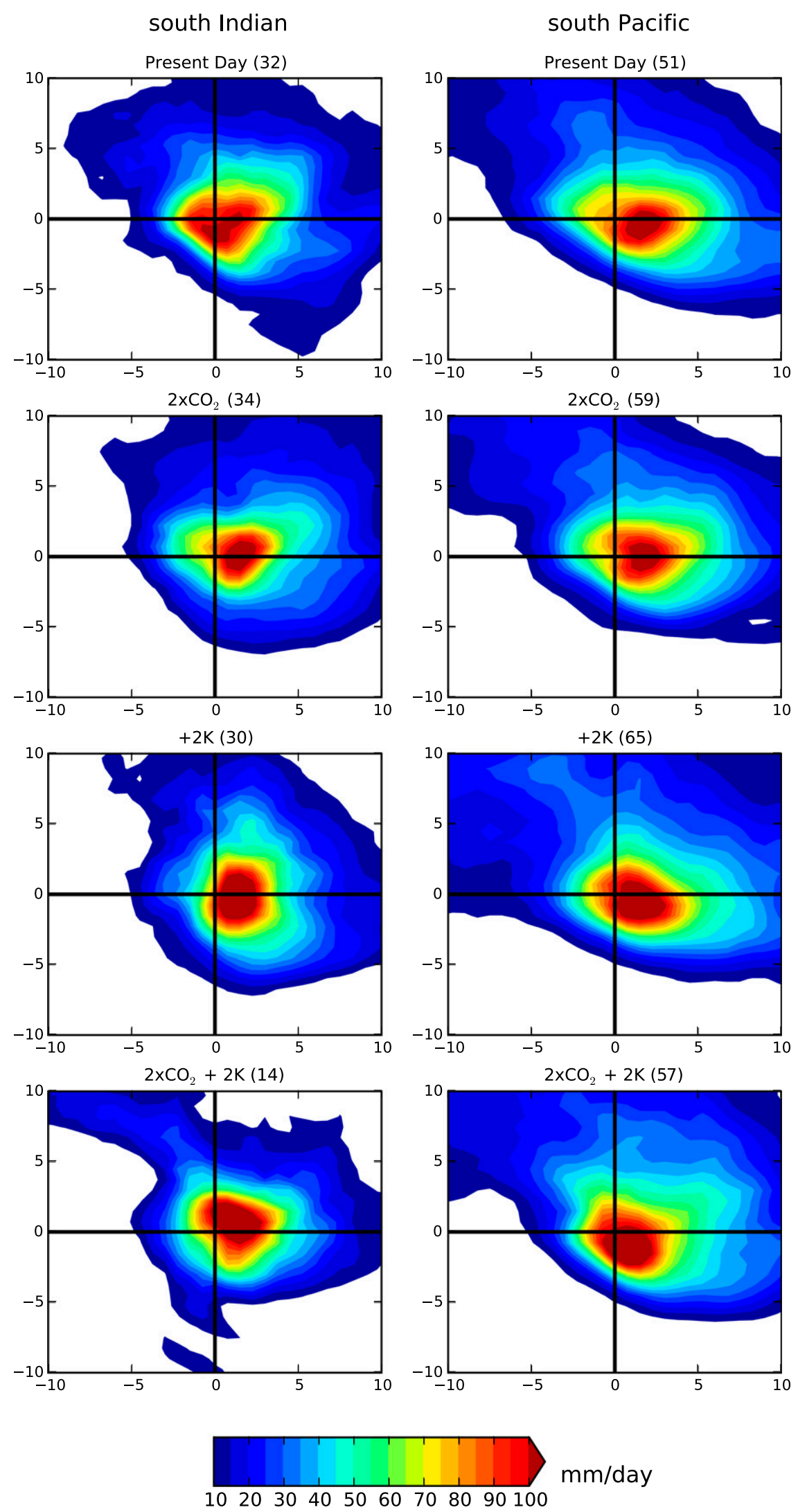

FIG. 9. As in Fig. 6, but for the CMCC model. 

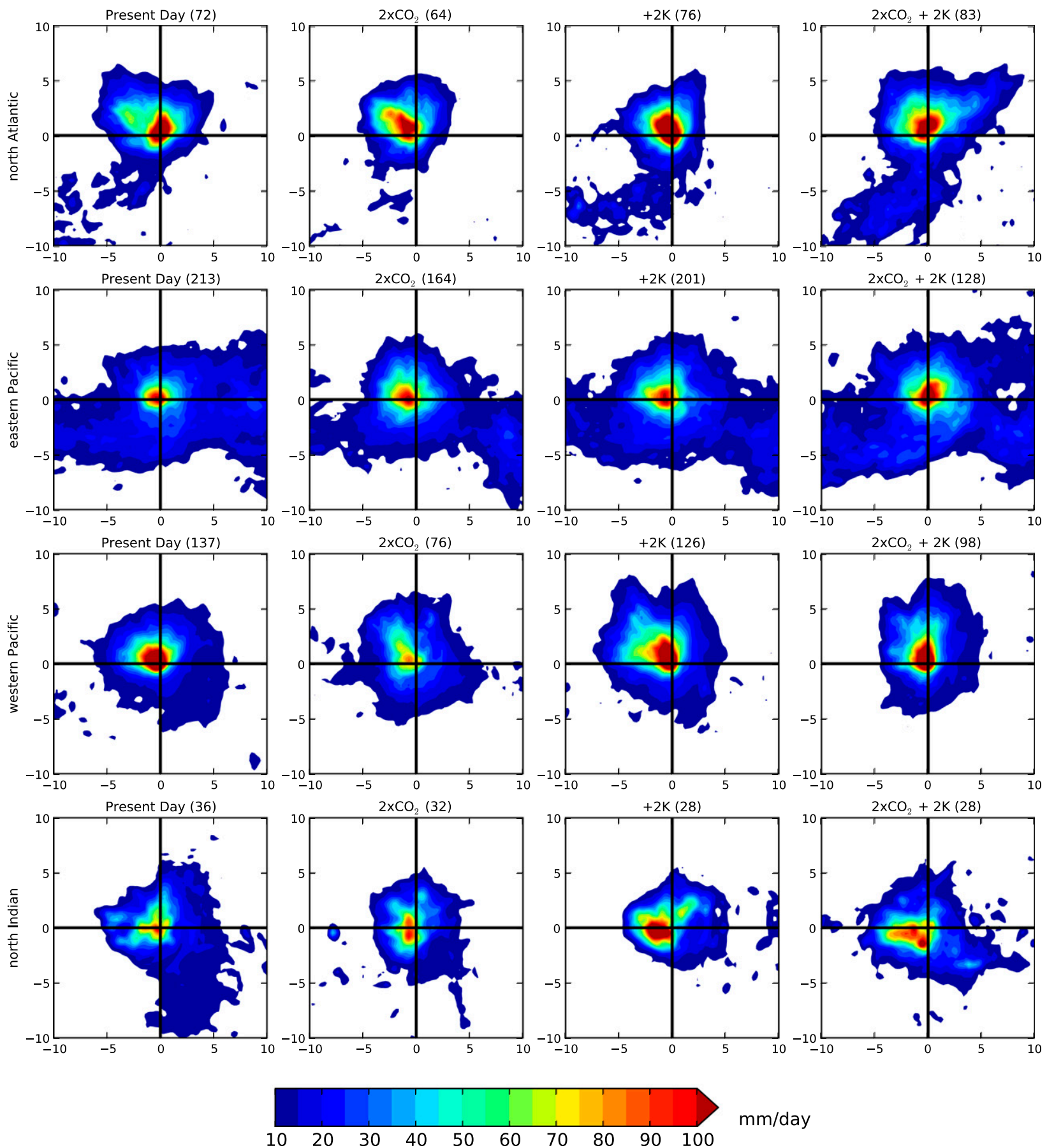

FIG. 10. As in Fig. 4, but for the CAM5. Note that the color bar extends over twice the range in Fig. 4.

there is not the clear enhancement in rainfall rates as we move $100-300 \mathrm{~km}$ from the center of circulation discussed for the GFDL model and reported in observational studies (e.g., Lonfat et al. 2004; Jiang et al. 2008). We can also clearly see the changes in rainfall profiles in response to the different scenarios. Based on the GFDL and the CMCC models and published studies (e.g., Sugi and Yoshimura 2004; Yoshimura and Sugi 2005), we would have expected a decrease in rainfall associated with a $\mathrm{CO}_{2}$ doubling. The response to increasing global SST is generally consistent with the other models.

Figure 12 shows the composite mean daily TC rainfall rate patterns for the basins in the Southern 

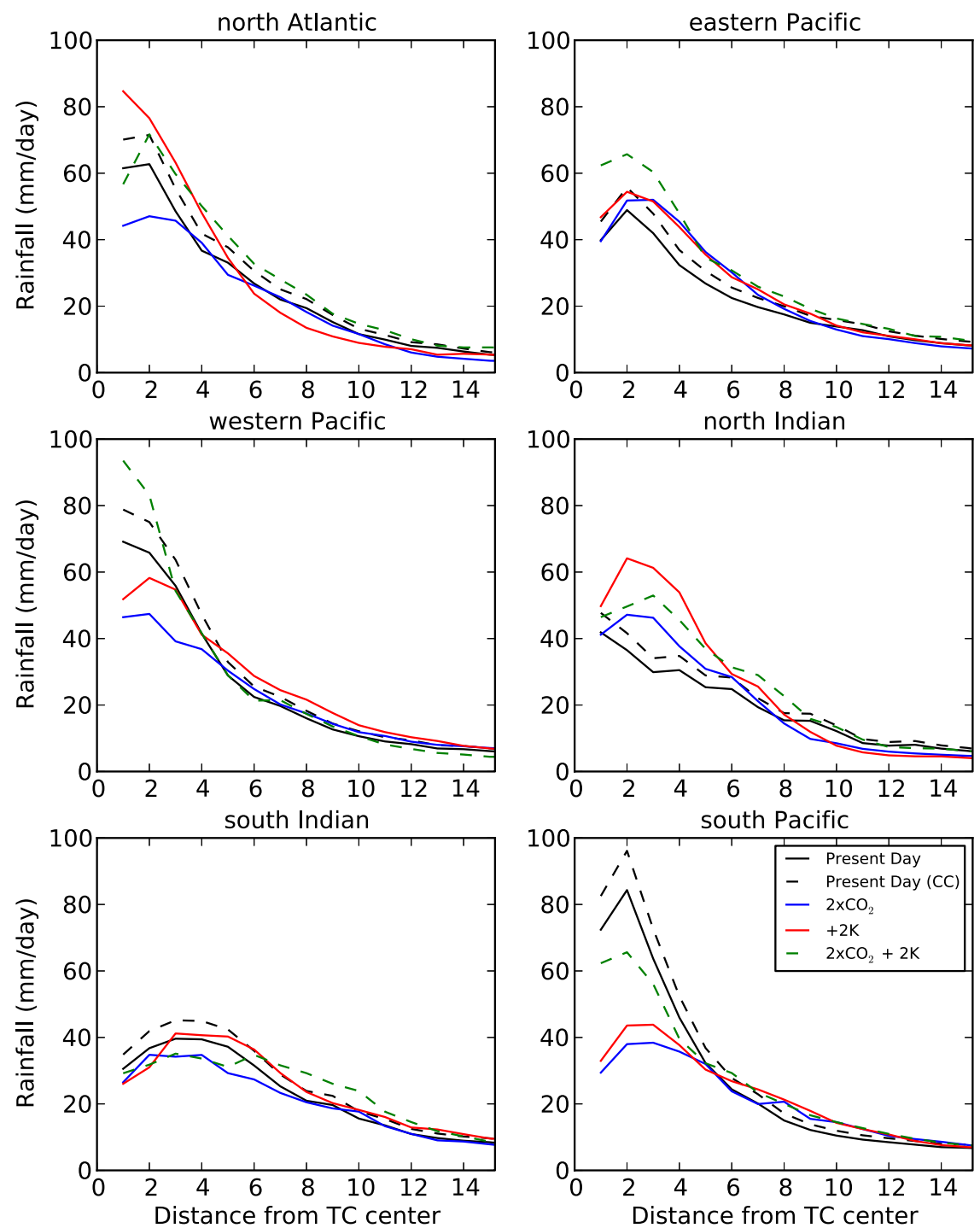

FIG. 11. As in Fig. 5, but for the CAM5. Note that $0.5^{\circ}$ bins are used instead of the $1^{\circ}$ bins used in Figs. 5 and 8.

Hemisphere for the CAM5. The results for the Present Day climate are similar to the observational record, with the same orientation and larger rainfall associated with the storms in the South Pacific rather than in the south Indian Ocean basin. For both basins, there is an overall decrease in TC rainfall rates for the $2 \times \mathrm{CO}_{2}$ scenario (Table 1 ). In the $+2 \mathrm{~K}$ case, there is an increase in TC rainfall for the south Indian Ocean and a marginal decrease for the South Pacific. Finally, more TC rainfall is generally associated with the $2 \times \mathrm{CO}_{2}+$ $2 \mathrm{~K}$ scenario.

The TC rainfall profiles based on the CAM5 for the two basins in the Southern Hemisphere show similarities and differences with respect to the other models. For the south Indian Ocean basin, there is not a large degree of variability among scenarios (see Figs. 5 and 8 for comparison with the GFDL and CMCC models). On the other hand, the median profiles for the TCs in the South Pacific suggest an overall reduction in TC rainfall in the three warming scenarios compared to the Present Day run, in particular close to the center of circulation. This response is different from what is observed in the other models regardless of the ocean basin. Further work is necessary to assess what the possible causes for the discrepancies between CAM5 and the GFDL and CMCC models are in the southern Pacific. Similar to what was found for the CMCC and GFDL models, it is difficult to interpret the results associated with the $+2 \mathrm{~K}$ scenario in terms of a simple Clausius-Clapeyron relationship scaling argument. 

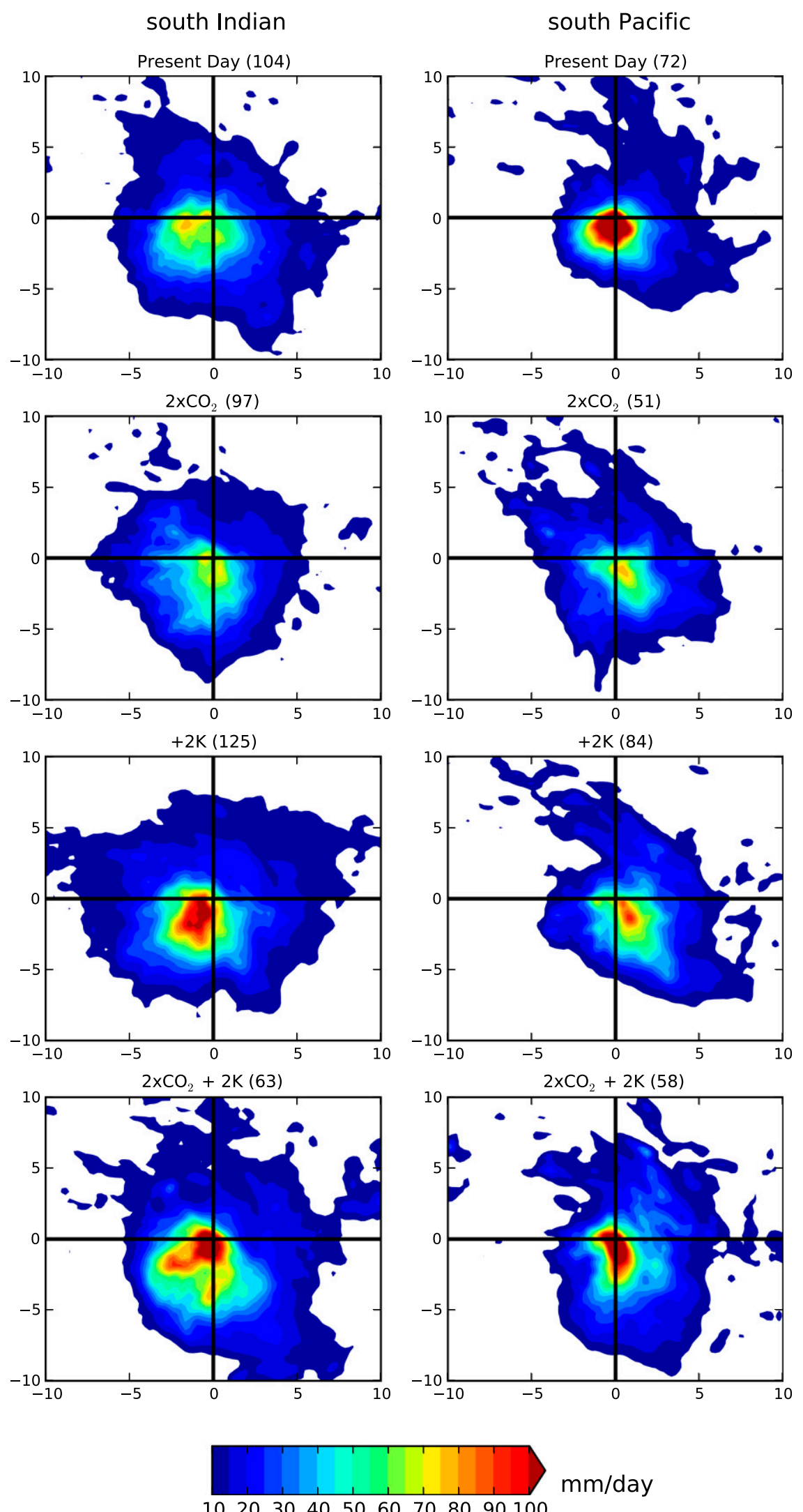

FIG. 12. As in Fig. 6, but for the CAM5. 


\section{Conclusions}

This study aimed to examine potential changes in rainfall associated with TCs at the global scale under different idealized global-scale perturbations. Results are based on three state-of-the-art atmospheric models (GFDL, CMCC, and CAM5) and three idealized perturbation atmospheric general circulation experiments (the radiative perturbation from doubling $\mathrm{CO}_{2}$ but keeping SST fixed, increasing the global SST by $2 \mathrm{~K}$, and a combination of the two).

An important step we undertook prior to the examination of the models' response to the different scenarios involved the assessment of the models' capability in reproducing the TC rainfall patterns in the observational records. Our findings suggest that these models are able to characterize the rainfall rate distribution associated with TCs reasonably well, both in terms of rainfall mean spatial composites and radial profiles. Our results, however, also indicate that there are discrepancies between modeled and observed TC rainfall. These discrepancies are related to both the location of the rainfall maximum and the rainfall magnitudes. Despite the relevance of the TC rainfall hazard, it appears that the model evaluation of the rainfall fields is generally lacking in a number of studies describing modeling of TC activity. We hope that this study could represent a first step toward a more comprehensive and widespread effort in assessing the skill of models in reproducing the rainfall properties associated with TCs.

With these model limitations in mind, we examined how TC rainfall would change in response to three forcing perturbations. Even though we highlighted some differences among models and basins, our results point to a reduction in composite TC rainfall rates (both in terms of spatial extent and magnitude) in direct response to a doubling in $\mathrm{CO}_{2}$, with SSTs remaining unchanged. On the other hand, a $2-\mathrm{K}$ global increase in SST points to the opposite result, with an overall increase in TC rainfall rates in all models. The spatial structure of the precipitation changes is less consistent than the spatially averaged changes, and we found that there are no consistent patterns among basins and distance from the center of circulation. Results at the global and hemispheric scales point to an average TC rainfall reduction when doubling $\mathrm{CO}_{2}$ on the order of $5 \%$, and an increase associated with a global warming of the SST by $2 \mathrm{~K}$ (both alone and in combination with $\mathrm{CO}_{2}$ doubling) on the order of $10 \%-20 \%$. For individual basins, the response seen in the global and hemispheric means is recovered, although with slightly more intermodel spread, and some interbasin differences. However, the overall tendency of the rainfall in the idealized perturbations is recovered across most basins for all models (Table 1), including the increase in response to a combined doubling of $\mathrm{CO}_{2}$ and an increase in global SST. There are indications that the response to both doubling of $\mathrm{CO}_{2}$ and 2-K warming together is not a linear sum of the responses to each forcing agent individually (Table 1), with the area-averaged increase in TC rainfall in response to both forcing agents often exceeding the increase in response to a $2-\mathrm{K}$ increase aloneeven though the response to $\mathrm{CO}_{2}$ increases alone is for a precipitation decrease. Because this result was unexpected to us, and because of the relatively small sample size, we choose to stop at remarking on its apparent existence, but leave further exploration and assessment of its mechanisms - to the extent that it is real-to future work.

These results add to an expectation that greenhouse gas-induced tropical warming should lead to an increase in rainfall rates of individual TCs (e.g., Knutson and Tuleya 2004; Knutson et al. 2010, 2013). Currentgeneration GCMs project, under a wide range of projected twenty-first century forcing scenarios, a robust warming of the tropics and tropical cyclone basins over the twenty-first century (e.g., Zhao et al. 2009; Vecchi and Soden 2007; Villarini and Vecchi 2012; Knutson et al. 2013). Based on these projections, an increase in SST by $2 \mathrm{~K}$ over their study area is within the realm of possibilities-arising largely from, and accompanied by, increases in greenhouse gases. Our results indicate that the decreases in TC precipitation rates from $\mathrm{CO}_{2}$ increases alone are not sufficient, in these three GCMs, to compensate for the SST-driven increases in TC rainfall rates. If current GCM projections of tropical warming and the rainfall modeling results described here and elsewhere are realized, then the hazard associated with rainfall from individual TCs should be increasing over the course of this century.

Acknowledgments. This work was carried out as part of a Hurricane and Climate Working Group activity supported by the U.S. CLIVAR. We acknowledge the support provided by Naomi Henderson, who downloaded and organized the data at the Lamont data library. Gabriele Villarini and David Lavers acknowledge financial support from the Iowa Flood Center, IIHRHydroscience \& Engineering. This material is based in part upon work supported by the National Science Foundation under Grant AGS-1262099 (Gabriele Villarini and Gabriel A. Vecchi), and in part from the Italian Ministry of Education, University and Research and the Italian Ministry of Environment, Land and Sea under the GEMINA project (Enrico Scoccimarro). Michael Wehner was supported by the Regional and Global Climate Modeling Program of the Office of Biological 
and Environmental Research in the Department of Energy Office of Science under Contract DE-AC0205CH11231. CAM5 calculations were performed at the National Energy Research Supercomputing Center (NERSC) at the Lawrence Berkeley National Laboratory.

\section{REFERENCES}

Bacmeister, J. T., M. F. Wehner, R. B. Neale, A. Gettelman, C. Hannay, P. H. Lauritzen, J. M. Caron, and J. E. Truesdale, 2014: High-resolution climate simulations using the Community Atmosphere Model (CAM). J. Climate, 27, 3073-3099, doi:10.1175/CLI-D-13-00387.1.

Bretherton, C. S., and S. Park, 2009: A new moist turbulence parameterization in the Community Atmosphere Model. J. Climate, 22, 3422-3448, doi:10.1175/2008JCLI2556.1.

_, J. R. McCaa, and H. Grenier, 2004: A new parameterization for shallow cumulus convection and its application to marine subtropical cloud-topped boundary layers. Part I: Description and 1D results. Mon. Wea. Rev., 132, 864-882, doi:10.1175/ 1520-0493(2004)132<0864:ANPFSC >2.0.CO;2.

Camargo, S. J., A. G. Barnston, and S. E. Zebiak, 2005: A statistical assessment of tropical cyclone activity in atmospheric general circulation models. Tellus, 57A, 589-604, doi:10.1111/ j.1600-0870.2005.00117.x.

Chan, K. T. F., and J. C. L. Chan, 2012: Size and strength of tropical cyclones as inferred from QuickSCAT data. Mon. Wea. Rev., 140, 811-824, doi:10.1175/MWR-D-10-05062.1.

Czajkowski, J., K. Simmons, and D. Sutter, 2011: An analysis of coastal and inland fatalities in landfalling U.S. hurricanes. Nat. Hazards, 59, 1513-1531, doi:10.1007/s11069-011-9849-x.

—, G. Villarini, E. Michel-Kerjan, and J. A. Smith, 2013: Determining tropical cyclone inland flooding loss on a large-scale through a new flood peak ratio-based methodology. Environ. Res. Lett., 8, 044056, doi:10.1088/1748-9326/8/4/044056.

Hart, R. E., and J. L. Evans, 2001: A climatology of the extratropical transition of Atlantic tropical cyclones. J. Climate, 14, 546-564, doi:10.1175/1520-0442(2001)014<0546:ACOTET>2.0.CO;2.

Held, I. M., and M. Zhao, 2011: The response of tropical cyclone statistics to an increase in $\mathrm{CO}_{2}$ with fixed sea surface temperatures. J. Climate, 24, 5353-5364, doi:10.1175/JCLI-D-11-00050.1.

Huffman, G. J., R. F. Adler, M. Morrissey, D. T. Bolvin, S. Curtis, R. Joyce, B. McGavock, and J. Susskind, 2001: Global precipitation at one-degree daily resolution from multisatellite observation. J. Hydrometeor., 2, 36-50, doi:10.1175/ 1525-7541(2001)002<0036:GPAODD>2.0.CO;2.

Jiang, H., J. B. Halverson, J. Simpson, and E. J. Zipser, 2008: Hurricane "rainfall potential" derived from satellite observations aids overland rainfall prediction. J. Appl. Meteor. Climatol., 47, 944-959, doi:10.1175/2007JAMC1619.1.

Jonkman, S. N., B. Maaskant, E. Boyd, and M. L. Levitan, 2009: Loss of life caused by the flooding of New Orleans after Hurricane Katrina: Analysis of the relationship between flood characteristics and mortality. Risk Anal., 29, 676-698, doi:10.1111/j.1539-6924.2008.01190.x.

Knapp, K. R., M. C. Kruk, D. H. Levinson, H. J. Diamond, and C. J. Neumann, 2010: The International Best Track Archive for Climate Stewardship (IBTrACS): Unifying tropical cyclone data. Bull. Amer. Meteor. Soc., 91, 363-376, doi:10.1175/ 2009BAMS2755.1.
Knutson, T. R., and R. E. Tuleya, 2004: Impact of $\mathrm{CO}_{2}$-induced warming on simulated hurricane intensity and precipitation: Sensitivity to the choice of climate model and convective parameterization. J. Climate, 17, 3477-3495, doi:10.1175/ 1520-0442(2004)017<3477:IOCWOS > 2.0.CO;2.

— J. J. Sirutis, S. T. Garner, I. M. Held, and R. E. Tuleya, 2007: Simulation of the recent multidecadal increase of Atlantic hurricane activity using an 18-km-grid regional model. Bull. Amer. Meteor. Soc., 88, 1549-1565, doi:10.1175/BAMS-88-10-1549.

— , and Coauthors, 2010: Tropical cyclones and climate change. Nat. Geosci., 3, 157-163, doi:10.1038/ngeo779.

— twenty-first-century Atlantic hurricane activity: CMIP3 and CMIP5 model-based scenarios. J. Climate, 26, 6591-6617, doi:10.1175/JCLI-D-12-00539.1.

Kunkel, K. E., D. Easterling, D. A. R. Kristovich, B. Gleason, L. Stoecker, and R. Smith, 2010: Recent increases in U.S. heavy precipitation associated with tropical cyclones. Geophys. Res. Lett., 37, L24706, doi:10.1029/2010GL045164.

Lau, W. K. M., and Y. P. Zhou, 2012: Observed recent trends in tropical cyclone rainfall over the North Atlantic and the North Pacific. J. Geophys. Res., 117, D03104, doi:10.1029/ 2011JD016510.

Lin, S. J., and R. B. Rood, 1996: Multidimensional flux-form semiLagrangian transport schemes. Mon. Wea. Rev., 124, 20462070, doi:10.1175/1520-0493(1996)124<2046:MFFSLT>2.0.CO;2.

Lonfat, M., F. D. Marks, and S. S. Chen, 2004: Precipitation distribution in tropical cyclones using the Tropical Rainfall Measuring Mission (TRMM) Microwave Imager: A global perspective. Mon. Wea. Rev., 132, 1645-1660, doi:10.1175/ 1520-0493(2004)132<1645:PDITCU>2.0.CO;2.

Mendelsohn, R., K. Emanuel, S. Chonabayashi, and L. Bakkensen, 2012: The impact of climate change on global tropical cyclone damage. Nat. Climate Change, 2, 205-209, doi:10.1038/ nclimate1357.

Neale, R. B., J. H. Richter, and M. Jochum, 2008: The impact of convection on ENSO: From a delayed oscillator to a series of events. J. Climate, 21, 5904-5924, doi:10.1175/2008JCLI2244.1.

_ , and Coauthors, 2012: Description of the NCAR Community Atmosphere Model (CAM 5.0). NCAR Tech. Note NCAR/TN-486+STR, 282 pp. [Available online at http:// www.cesm.ucar.edu/models/cesm1.0/cam/docs/description/ cam5_desc.pdf.]

Nordeng, T. E., 1994: Extended versions of the convective parametrization scheme at ECMWF and their impact on the mean and transient activity of the model in the tropics. ECMWF Tech. Memo. 206, 41 pp.

Park, S., and C. S. Bretherton, 2009: The University of Washington shallow convection and moist turbulence schemes and their impact on climate simulations with the Community Atmosphere Model. J. Climate, 22, 3449-3469, doi:10.1175/2008JCLI2557.1.

Peduzzi, P., B. Chatenou, H. Dao, A. De Bono, C. Herold, J. Kossin, F. Mouton, and O. Nordbeck, 2012: Global trends in tropical cyclone risk. Nat. Climate Change, 2, 289-294, doi:10.1038/nclimate1410.

Pielke, R. A., J. Gratz, C. W. Landsea, D. Collins, M. A. Saunders, and R. Musulin, 2008: Normalized hurricane damage in the United States: 1900-2005. Nat. Hazards Rev., 9, 29-42, doi:10.1061/(ASCE)1527-6988(2008)9:1(29).

Prabhat, O. Ruebel, S. Byna, K. Wu, F. Li, M. Wehner, and W. Bethel, 2012: TECA: A parallel toolkit for extreme climate analysis. Procedia Comp. Sci., 9, 866-876, doi:10.1016/ j.procs.2012.04.093. 
Rappaport, E. N., 2000: Loss of life in the United States associated with recent tropical cyclones. Bull. Amer. Meteor. Soc., 81, 2065-2074, doi:10.1175/1520-0477(2000)081<2065: LOLITU $>2.3 . \mathrm{CO} ; 2$.

Rayner, N. A., D. E. Parker, E. B. Horton, C. K. Folland, L. V. Alexander, D. P. Rowell, E. C. Kent, and A. Kaplan, 2003: Global analyses of sea surface temperature, sea ice, and night marine air temperature since the late nineteenth century J. Geophys. Res., 108, 4407, doi:10.1029/2002JD002670.

Ren, F., G. Wu, W. Dong, X. Wang, Y. Wang, W. Ai, and W. Li, 2006: Changes in tropical cyclone precipitation over China. Geophys. Res. Lett., 33, L20702, doi:10.1029/2006GL027951.

Richter, J. H., and P. J. Rasch, 2008: Effects of convective momentum transport on the atmospheric circulation in the Community Atmosphere Model, version 3. J. Climate, 21, 1487-1499, doi:10.1175/2007JCLI1789.1.

Roeckner, E., and Coauthors, 2003: The atmospheric general circulation model ECHAM5. Part I: Model description. MPI Rep. 349, 127 pp. [Available online at https:/www.mpimet.mpg.de/ fileadmin/publikationen/Reports/max_scirep_349.pdf.]

_ , and Coauthors, 2006: Sensitivity of simulated climate to horizontal and vertical resolution in the ECHAM5 atmosphere model. J. Climate, 19, 3771-3791, doi:10.1175/ JCLI3824.1.

Scoccimarro, E., and Coauthors, 2011: Effects of tropical cyclones on ocean heat transport in a high-resolution coupled general circulation model. J. Climate, 24, 4368-4384, doi:10.1175/ 2011JCLI4104.1.

—, S. Gualdi, G. Villarini, G. Vecchi, M. Zhao, K. Walsh, and A. Navarra, 2014: Intense precipitation events associated with landfalling tropical cyclones in response to a warmer climate and increased $\mathrm{CO}_{2}$. J. Climate, doi:10.1175/JCLI-D-14-00065.1, in press.

Sugi, M., and J. Yoshimura, 2004: A mechanism of tropical precipitation change due to $\mathrm{CO}_{2}$ increase. J. Climate, 17, 238-243, doi:10.1175/1520-0442(2004)017<0238:AMOTPC>2.0.CO;2.

Taylor, K. E., R. J. Stouffer, and G. A. Meehl, 2012: An overview of CMIP5 and the experiment design. Bull. Amer. Meteor. Soc., 93, 485-498, doi:10.1175/BAMS-D-11-00094.1.

Tiedtke, M., 1989: A comprehensive mass flux scheme for cumulus parametrization in large-scale models. Mon. Wea. Rev., 117, 1779-1800, doi:10.1175/1520-0493(1989)117<1779: ACMFSF $>2.0 . \mathrm{CO} ; 2$.

Vecchi, G. A., and B. J. Soden, 2007: Effect of remote sea surface temperature change on tropical cyclone potential intensity. Nature, 450, 1066-1070, doi:10.1038/nature06423.
Villarini, G., and G. A. Vecchi, 2012: Twenty-first-century projections of North Atlantic tropical storms from CMIP5 models. Nat. Climate Change, 2, 604-607, doi:10.1038/ nclimate 1530

Walsh, K. J. E., 1997: Objective detection of tropical cyclones in high-resolution analyses. Mon. Wea. Rev., 125, 1767-1779, doi:10.1175/1520-0493(1997)125<1767:ODOTCI >2.0.CO;2.

—, M. Fiorino, C. W. Landsea, and K. L. McInnes, 2007: Objectively determined resolution-dependent threshold criteria for the detection of tropical cyclones in climate models and reanalyses. J. Climate, 20, 2307-2314, doi:10.1175/JCLI4074.1.

— S. Lavender, E. Scoccimarro, and H. Murakami, 2013: Resolution dependence of tropical cyclone formation in CMIP3 and finer resolution models. Climate Dyn., 40, 585-599, doi:10.1007/s00382-012-1298-z.

Ying, M., B. Chen, and G. Wu, 2011: Climate trends in tropical cyclone-induced wind and precipitation over mainland China. Geophys. Res. Lett., 38, L01702, doi:10.1029/2010GL045729.

Yoshimura, J., and M. Sugi, 2005: Tropical cyclone climatology in a high-resolution AGCM-Impacts of SST warming and $\mathrm{CO}_{2}$ increase. SOLA, 1, 133-136, doi:10.2151/sola.2005-035.

Zhang, G. J., and N. A. McFarlane, 1995: Sensitivity of climate simulations to the parameterization of cumulus convection in the Canadian Climate Centre general circulation model. Atmos.-Ocean, 33, 407-446, doi:10.1080/07055900.1995.9649539.

Zhang, Q., L. Wu, and Q. Liu, 2009: Tropical cyclone damages in China 1983-2006. Bull. Amer. Meteor. Soc., 90, 489-495, doi:10.1175/2008BAMS2631.1.

Zhao, M., and I. M. Held, 2010: An analysis of the effect of global warming on the intensity of Atlantic hurricanes using a GCM with statistical refinement. J. Climate, 23, 6382-6393, doi:10.1175/2010JCLI3837.1.

, S.-J. Lin, and G. A. Vecchi, 2009: Simulations of global hurricane climatology, interannual variability, and response to global warming using a 50-km resolution GCM. J. Climate, 22, 6653-6678, doi:10.1175/2009JCLI3049.1.

,-- , and -2012 : Some counterintuitive dependencies of tropical cyclone frequency on parameters in a GCM. J. Atmos. Sci., 69, 2272-2283, doi:10.1175/JAS-D-11-0238.1.

, and Coauthors, 2013: Robust direct effect of increasing atmospheric $\mathrm{CO}_{2}$ concentration on global tropical cyclone frequency: A multi-model inter-comparison. U.S. CLIVAR Variations, Vol. 11 (3), International CLIVAR Project Office, Southampton, United Kingdom, 17-23. [Available online at http://www.usclivar.org/sites/default/files/USCLIVAR_ VARIATIONS_11_3_Fall2013.pdf.] 